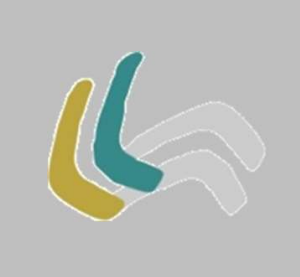

\title{
“MEU LIVRO DE CORDEL" ATRAVÉS DE TEMPOS, VERSOS E MEMÓRIAS: RESISTÊNCIAS EM IDENTIDADES
}

\section{"MEU LIVRO DE CORDEL" THROUGH TIMES, VERSES AND MEMORIES: RESISTANCE IN IDENTITIES}

\author{
Meire Oliveira Silva ${ }^{1}$ \\ Universidade Federal do Maranhão
}

Resumo: A obra de Cora Coralina ressoa na Literatura Brasileira como uma das mais genuínas vozes de mulheres a elevar a poesia popular e a cultura regional ao lugar de inquietações contemporâneas que atestam o caráter universal de suas produções. Mulher de educação tradicional e, talvez por esse motivo, desde cedo afastada das letras, conheceu o casamento, a rejeição familiar, o ofício de doceira e algum reconhecimento após o lançamento de seu primeiro livro apenas na maturidade, após os 70 anos de idade. No entanto, sua inclinação precoce à literatura junto a um olhar arguto para seu momento histórico a levou à realização de uma obra que transita por diversas temáticas, estilos e pautas entre tramas que aludem ao narrativo, ao lírico e ao memorialístico dos registros de lugares que reverberam como microcosmos de eventos históricos cujos ecos incidem sobre a contemporaneidade confirmando a atualidade de sua escrita. Assim, a análise de Meu livro de cordel (1976) alude a questões que dialogam (BAKHTIN, 1997) com os estudos de Literatura (CANDIDO, 2006), gênero (MACHADO, 2003) e memória (CANDAU, 2014).

Palavras-Chave: Mulher; Identidade; Poesia; Discurso; Memória.

1 Endereço eletrônico: meire_oliveira@uol.com.br. 
Abstract: Cora Coralina's work resonates in Brazilian Literature as one of the most genuine voices of women to elevate popular poetry and regional culture to the place of contemporary concerns that attest to the universal character of her productions. A woman of traditional education and, perhaps for this reason, from an early age away from writing, she experienced marriage, family rejection, worked as a sweet baker and found some recognition after the release of her first book only in her maturity, after her 70s. However, her early inclination to literature together with a keen eye for her historical moment led her to carry out a work that moves through various themes, styles and guidelines between plots that allude to the narrative, the lyrical and the memorial of the records of places that they reverberate as microcosms of historical events whose echoes focus on contemporaneity, confirming the actuality of her writing. Thus, the analysis of Meu Livro de Cordel (1976) alludes to issues that dialogue (BAKHTIN, 1997) with studies in Literature (CANDIDO, 2006), genre (MACHADO, 2003) and memory (CANDAU, 2014).

Keywords: Woman; Identity; Poetry; Speech; Memory.

\section{INTRODUÇÃO}

A escritora goiana Ana Lins dos Guimarães Peixoto Bretas assinou como Cora Coralina a obra cuja escrita é permeada por memórias. Como poeta popular, ainda que publicada muito tardiamente, fez história no país. Assim, foi elevada ao patamar de uma das maiores vozes da Literatura Brasileira. Frequentou a escola somente nas séries iniciais, apesar de escrever desde muito jovem. Chegou a ocupar a cadeira número cinco, como participante fundadora da Academia Feminina de Letras e Artes de Goiás. Na carreira literária, começou de forma oficial apenas aos 76 anos.

De origem nordestina herdada do pai, a escritora deixou memórias em forma de poesia ao adotar gêneros populares que remetem à oralidade. Como muitas mulheres do Brasil, após exercer funções sociais não reconhecidas pela sociedade, também utilizou sua voz para, de maneira singela, desvelar outras vozes ancestrais que ainda ecoam na história do país (PAZ, 1972). A trajetória de vida, que acaba reverberando em seu percurso literário, alude a delicadas questões sobre ser uma mulher pobre no Brasil, nação onde os entrelaçamentos de opressões manifestam-se também na opressão dirigida aos idosos. Sua história é também de luta ao resistir a tantos abusos e ainda extrair lirismo de todas essas adversidades. 
Analisar sua trajetória significa, portanto, voltar-se à compreensão de uma escrita considerada dissonante justamente por ser imbuída das diversas realidades nacionais que são reverberadas em vozes silenciadas ao longo da história, mas que resistem em novos levantes de denúncia e de afirmação da existência de identidades (CANDAU, 2014) que a história oficial reluta em reconhecer. A inspiração de sua obra para outras mulheres se faz presente na contemporaneidade afirmando a necessidade de resgate de memórias (RICOEUR, 2007) cujas autorias femininas, no que se refere aos tensionamentos identitários da escrita permeada pelo ser-mulher, deixaram legados inegáveis. Sendo assim, pretende-se, por meio da retomada de Meu livro de cordel (1976), segunda obra da autora, analisar como promoveu dialogismos (BAKHTIN, 1997) abrindo espaço para a ressonância de mais vozes atemporais presentes em memórias que não permitem o apagamento de narrativas que, em mosaico, recriam a força de um povo. Sua própria vivência de trabalhadora leva seu ofício de doceira, entre o artesanato, a arte, a delicadeza e a simplicidade para sua poesia repleta de memórias que se apresentam cada vez mais atuais.

\section{TRAMAS DE MEMÓRIAS E HISTÓRIAS}

Cora Coralina consagrou-se como a poeta popular brasileira que uniu memórias ao presente para comunicar suas experiências (RICOUER, 2007) atreladas a fatos cotidianos com signos poéticos que conferem lirismo aos relatos permeados por simplicidade que não abdicam dos recursos estilísticos da forma lírica (BOSI, 1977). Tais aspectos precisam ser examinados considerando-se o momento histórico no qual situa-se a sua produção cujos ecos revisitam novas modalidades de produção poética marginalizada e até esquecida pela própria academia que, aos poucos, vai silenciando as vozes das mulheres ao longo da História e apagando seus escritos e suas experiências, apesar dos esforços e 
avanços da crítica literária feminista, desde os anos 1970, para buscar reverter esse quadro. É preciso atentar para o fato de que sua obra abriu caminhos para se pensar uma forma original de poesia brasileira porque nela estão espalhados espaços do país que revelam memórias ancoradas em fissuras históricas cujas marcas atemporais desnudam um país que não se quer desvelar.

Seu primeiro livro, Poemas dos Becos de Goiás e Estórias Mais (1965), dividese em duas partes e formas, entre a prosa e a poesia. Porém, ambas narram estórias e histórias da Cidade de Goiás, onde nasceu, e fez motivo de suas criações. Seu olhar oscila entre as memórias e a observação do presente e já dá o tom do que seria a sua publicação seguinte, Meu Livro de Cordel. Nessa segunda obra que, de certa forma, condensa muito de sua produção literária, a poeta retoma memórias e reconstrói espaços imagéticos e líricos, valendo-se de intertextualidades, dialogismos, polifonias e metáforas. Autora de contos, poemas e crônicas, sua escrita nesse livro mescla diversos gêneros em uma linguagem prosaica que remete ao cotidiano e aos imbricados caminhos da memória.

Os temas geralmente abordados pela escritora focalizam as vivências interioranas em um cotidiano que reúne personagens relegados à invisibilidade porque desafiam o que seria tema de poesia. Mais ainda, subvertem as expectativas quanto às classificações que insistem em relegar à escrita feminina a submissão, a delicadeza e a ocupação de estereótipos de gênero que limitariam seu olhar sobre o mundo. No entanto, o ser-mulher de sua poesia se manifesta no extravasamento de seus desejos e de seu olhar para o outro, aquele julgado não matéria poética. Na atenção para o considerado disforme, afeito à escuridão, aos lugares recônditos e meditativos, insurgem motes que norteiam seus versos fazendo emergir mulheres, crianças e memórias que atravessam a história da cidade de Goiás. Em suas pedras, rios e pontes desvelam-se passagens de sua 
trajetória desde o surto da extração de ouro até o declínio dessa fase que culmina na decadência da região que marca o local, no século $X X$, por miséria.

É um país que se desenha na revelação de uma voz que perpassa outras múltiplas vivências e lugares. Sua poesia ganha então contornos universais, ao mesclar a tradição oral da contadora de causos à saga épica das narrativas cheias de detalhes e personagens. E a linguagem aparentemente simples desemboca em reflexões que remetem ao próprio fazer poético artesanal, até rudimentar, por extrair da matéria prima da palavra contornos inusitados que transitam da poesia à prosa subvertendo os gêneros literários como em um modo despretensioso de escrever.

O prólogo da obra se confunde com uma epígrafe de si mesma nas memórias da autora, narradas a partir do resgate de seu passado (NORA, 1993). Ao assumir a escrita do cordel, Cora Coralina reporta-se à cultura popular e ao nordeste de seus antepassados corporificados em vozes de menestréis. Declara que escreve "Pelo amor que tenho a todas as estórias e poesias de Cordel", na abertura da obra, em personificação que alude a questões literárias e históricas, a fim de reorganizar as lembranças de suas raízes familiares com as memórias de seu pai, "numa ligação profunda/e obstinada com todos os anônimos/menestréis nordestinos, povo da minha/casta, meus irmãos do Nordeste rude,/de onde um dia veio meu Pai para/que eu nascesse e tivesse vida" em confissão e homenagem às reminiscências que ultrapassam elos temporais (BENJAMIN, 1994).

Desde as redescobertas da própria poesia a partir de Pablo Neruda, já na maturidade, o arrebatamento pela surpresa do poder dos segredos da literatura começa a dar sinais em seus textos. A partir do extravasamento "Sou mulher como outra qualquer/ Venho do século passado/ e trago todas as idades" (CORALINA, 2021, p. 48), vê-se a liberação para o questionamento em torno das "ruas do Destino/ procurando meu signo" em uma busca de si mesma e da sua existência como novas possibilidades de vivências irmanadas ao outro: "Procurei 
a morada da Fortaleza./ Ela me fez entrar: deu-me veste nova,/ perfumou-me os cabelos,/ fez-me beber de seu vinho./ Acertei o meu caminho" (CORALINA, 2012, p. 55). Em sua trajetória, na construção da poeta, espalha-se a condição de mulher tentando compreender de onde fala e a quem se comunica.

Os títulos dos poemas elencados em Meu livro de cordel já anunciam a atmosfera de resgate do passado permeado pelo intimismo confessional de memórias que se desdobram em ecos de experiências coletivas. E tais questões dizem respeito às histórias de vida da escritora. Dividido em duas partes, a obra parece remeter inicialmente a uma vivência coletiva que posteriormente é individualizada em movimentos oscilatórios que se confundem entre as confissões e os exercícios de alteridade, como demonstra o polifônico poema "Cantoria" que reúne vozes múltiplas entre "lavadeiras", "velha pobrezinha" e "mulher da vida" para escorrer em lamentos históricos alusivos a um passado que marcou a história da região, em “ouro enterrado" detentor da decadência certeira que reduziria a região à prática agropecuária como subsistência e sina já que "cidade largada" a versar sobre "burro de cangalha", "lenha despejada" e "vacas pastando" como a própria voz do poema que, com "escoras" silencia na observação da paisagem: “[...] aqui vou ficando...” (CORALINA, 2012, p. 12).

Em “Das Pedras" da cidade de Goiás, antiga capital do estado homônimo, a cartografia da região se confunde com diários, cartas e bilhetes de confissões que resgatam do rés do chão das pedras - físicas e metafóricas - a pungência de lidar com os entraves da existência ao pronunciar: "Entre pedras que me esmagavam/levantei a pedra rude dos meus versos". Logo, sua escrita movimenta-se parecendo oferecer novas possibilidades de existências na superação da condição humana, nem que seja por meio da poesia ao tomar da experiência nuances de realização. Ao filosofar sobre os fenômenos naturais, encarna também crenças antigas acerca da influência dos astros na existência humana por meio da "Lua-luar" multifacetada em passagens transformadas que 
sugerem transformações “Lua boa./ Lua ruim./ Lua de chuva./ Lua de sol./ Lua das gestações do amor" a desnudar-se e convidar também ao desnudamento do leitor e do próprio eu poemático advindo “Do acaso, do passatempo/ irresistível,/ responsável, irresponsável" na escrita de sua experiência que, aos poucos, estabelece diálogo e tentativas de desvelamento. É também a compreensão de um discurso aparentemente avesso a dissimulações da intenção comunicativa. Sempre em busca de uma identificação para responder às indagações empreendidas ao longo dos poemas caminhando rumo a uma só mensagem da mulher irmanada e confundida à própria paisagem e às vivências locais e atemporais.

Em "Variação" a poesia se alarga estabelecendo elos entre a literatura, em seu próprio ato de criação, e os diálogos com outros fazeres poéticos. Entre intertextualidades, os versos desenham decalques de uma lírica genuína que se dilui em considerações acerca do exercício da escrita. Na retomada de motes populares da literatura que emana do povo em cantigas folclóricas e outras manifestações poéticas, o eu lírico tece uma rede de discursos que delineiam culturas diversas e experiências diversificadas (MACHADO, 2003).

Poderia se tratar somente de questões afeitas ao regionalismo, mas a lírica coraliniana parece ultrapassar certas barreiras geográficas, por mais que seu leitmotiv parta de Goiás para se derramar em memórias universais. Essa tradição regionalista apresenta-se expandida. Segundo Alfredo Bosi, o escritor romântico Bernardo Guimarães, ao ambientar sua prosa, partia de questões afeitas à oralidade para retratar porque

mistura elementos tomados à narrativa oral, os 'causos' e as 'estórias' de Minas e Goiás, com uma boa dose de idealização. Esta, embora não tão maciça como em Alencar, é responsável por uma linguagem adjetivosa e convencional na maioria dos quadros agrestes. (BOSI, 2015, p. 97) 
No entanto, a escrita de Cora Coralina parece superar expectativas estéticas geralmente atribuídas à descrição da paisagem e "das cores locais" (CANDIDO, 1993) que moldam as regiões retratadas literariamente em obras que tinham um caráter fundador. Ao retomar questões históricas e memorialísticas nos conturbados anos 1970 brasileiros, é possível apreender dessa literatura resistência para, ao contrário de Guimarães, retratar o país depreendido do microcosmo Goiás-Minas - berços da exploração mineradora colonial - um protesto, ainda que tímido ou inconsciente como "bandeira" de resistência às forças opressoras ao se tomar narrativas individuais de um Brasil tão múltiplo e desigual. Os adjetivos coralinianos, certeiros, mais do que servirem à ornamentação dos versos, veiculam imagens conflitantes de uma formação nacional complexa.

Sabendo-se do espaço como tópico essencial para a construção de tramas narrativas de cunho fictício ou ancorado na descrição dos fatos, é possível estabelecer pontos de contato com o enredo elaborado em consonância com o tempo localizado em um lugar histórico ou imaginário. Ainda que se desenrole no trânsito para localizar os movimentos entre personagens dentro de uma narrativa ancorada em tempo determinado e seja um "espaço real", essas construções perfazem uma concepção de trama literária que subverte as noções rígidas de cartografia e demarcação temporal. Essas reflexões encontram aporte na crítica literária. O New Criticism, o Estruturalismo Francês e o Formalismo Russo, por exemplo, insistem nessas questões fundamentais para a análise literária. Assim, é preciso compreender se tais elementos ultrapassam classificações tradicionais porque criações literárias atreladas a diversas bases epistemológicas, como as que resvalam em interpretações psicanalíticas ou memorialísticas, possivelmente configurem uma escrita testemunhal ajustada por um momento histórico pautado pela voz lírica que reverbera coletivamente. 
De outro modo, pretende-se examinar como o espaço e o tempo descritos na poesia de Cora Coralina, em Meu livro de cordel, talvez, possam dizer respeito a questões que, atravessadas pelos elementos memorialísticos, possam ser analisadas literariamente em uma chave mais ampla que promova diversas maneiras de se conceber o "lugar" ocupado pelos textos a partir da Teoria Literária, pensando sobretudo no cânone poético brasileiro e as correntes críticas que dele se ocuparam.

A poeta, natural de Cidade de Goiás, passou anos em São Paulo, após matrimônio conturbado não aceito por sua família. Seu primeiro livro, Poemas dos Becos de Goiás e outras Estórias Mais demonstra a dificuldade de inserção no universo literário, mesmo que as narrativas em torno de sua vida datem a sua escrita da adolescência e também o convite recusado para participar da Semana de Arte Moderna de 1922, como proibição do marido, anos mais velho e com o qual teve muitos filhos, sendo levada a contribuir para a subsistência da família como doceira e não à vida literária. Sua entrada para a Academia Feminina de Letras e Artes de Goiás não a integrou automaticamente à aceitação nacional, apesar do aval de Carlos Drummond de Andrade, que teceu extensos elogios à sua produção na imprensa e, quanto a isso, podem-se perceber nuances dialógicas com sua própria poesia, conforme aproxima Bosi:

A poesia resiste à falsa ordem, que é, a rigor, barbárie e caos, "esta coleção de objetos de não amor" (Drummond). Resiste ao contínuo "harmonioso" pelo descontínuo gritante; resiste ao descontínuo gritante pelo contínuo harmonioso. Resiste aferrando-se à memória viva do passado; e resiste imaginando uma nova ordem que se recorta no horizonte da utopia. (BOSI, 1977, p. 145)

Quando, em 1976, Meu livro de Cordel vem a público, sua escrita desperta curiosidade e sua trajetória de vida também. Não faltaram tentativas de estabelecer pontos de encontro entre a biografia e a produção literária que atreladas demonstram o inusitado da aproximação. E, de fato, sua escrita parece 
partir de experiências íntimas com as quais somente a subjetividade pode dialogar, resistindo aos "lugares" mormente destinados à poesia.

A palavra impõe-se categoricamente representativa de um lugar, para além de geográfica, identitária, por meio do engendramento dos signos que deslocam as classificações linguísticas para outras ordens que metaforicamente aludem à memória. Trata-se de uma forma de impedir a imposição do tempo que leva, apaga e silencia as narrativas do povo, pequenos relatos do cotidiano que não alcançam a grandeza da historicidade, mas compõem mosaicos de memórias individuais que falam ao coletivo como microcosmos do próprio país inserido em um tempo histórico confundido com o mítico em torno de sua formação. E o discurso de uma mulher ecoa em outras experiências para aludir ao encontro entre literatura e vida, já que memória e testemunho de si mesma configurada em escrita literária porque elaborada linguisticamente.

A partir das imagens bíblicas de "O Criador, vendo que/ a terra era boa,/ plantou um jardim/ de jabuticabeiras/ nas terras roxas/ de São Paulo/ da banda Oeste" (CORALINA, 2012, p. 22), o poema Jaboticabal (I) inicia. E, por meio de uma análise repleta de provocações linguísticas e históricas propostas, é possível entrever a polêmica questão da identidade nacional em profundo embate com a chamada História oficial de "fundação do país". A fecundação da terra denota sua ocupação patriarcal mesmo através da exploração da mão-de-obra imigrante para o plantio de café, a riqueza sustentadora do país a partir do sudeste do Brasil, no início do século XX. Os versos imbuídos de descrições irônicas sobre as famílias que fecundaram a terra demonstram um olhar ferino acerca do poder fálico da opressão escamoteada de conquista: “[...] tomassem da terra/e gerassem filhos". Nas novas possibilidades fonéticas e semânticas a figura paterna, entre os Pintos e o Patrimônio, como personificações e substantivos próprios que representam autoridade da Posteridade, também personificada como destino implacável: “E vieram:/ Pinto Ferreira e sua mulher./ Os Pintos.../ Avenida 
Pintos,/ a dádiva da Posteridade/ do velho fundador/ que doou o Patrimônio/ nos idos do passado" (CORALINA, 2012, p. 20).

A percepção diante da existência, sobretudo, da mulher situada em um contexto histórico-social permeado por nuances formadoras de sua própria paisagem transfigura-se como identificação com a terra - "A mulher é a terra terra de semear" (CORALINA, 2012, p. 60) -, fecunda, também selvagem, em chão de narrativas a confundir as identidades dos sujeitos e espaços em tempos que universalizam relatos. Em 43 poemas divididos em duas partes - 28 e 15 poemas - a sequência refere-se a uma trama memorialística de indivíduos mesclados à memória coletiva. E, entre essas memórias, emergem eventos situados em locais históricos e fictícios plenos de temas que aludem, concomitantemente, às questões sociais e de gênero, em um olhar que remete inclusive ao pós-colonialismo de reivindicar as vozes subalternizadas ancestralmente na história do país. Ainda que na utilização de uma lírica que não aparenta afetações teóricas, mas é pautada por vivências:

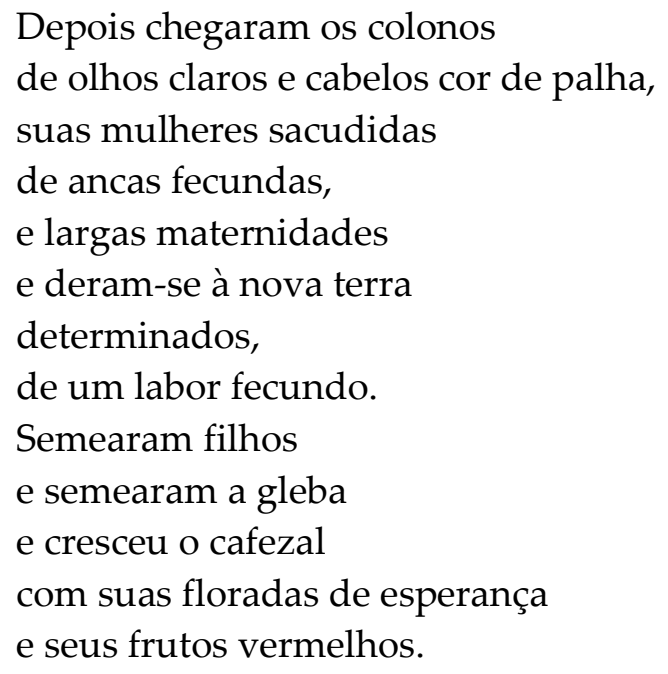

Os horrores do Holocausto entremeiam-se às dores das formações nacionais a partir de Minas Gerais, Goiás e outras pedras a metaforizar palcos de 
histórias que remetem a extermínios cotidianos de seres marginalizados pela sociedade:

O débito universal jamais quitado.

Perseguidos. Espoliados. Rejeitados.

Discriminados. Escravizados, Gaseados Redivivos.

Povo Heroico.

(CORALINA, 2012, p. 26)

Em passagens reiteradas, o tema dos judeus e da perseguição genocida se mantém:

Há muitos anos,

no fim da última guerra,

mais para o ano de 1945,

diziam os jornais de um navio fantasma

percorrendo os mares e procurando um porto.

(CORALINA, 2012, p. 27)

Entre tais passagens, imagens de crianças ("Criança pobre/ de pé no chão./ Suja, rasgada,/ despenteada./ Desmazelada./ Criada à toa, de roldão./ Cria de casebre,/ enxerto de galpão."), idosos, mulheres - prostitutas, velhas, jovens, abandonadas - descobrindo suas existências em pulsões (BEAUVOIR, 1990) corporais e psíquicas são desvelados. Na descrição identificadora entre a terra, os rios (fecundos, em outro tema recorrente em sua poesia) surge a terra irrigada por Rio(s) Vermelhos(s) metaforizado em fluxos sanguíneos que remetem à biofisiologia feminina ressignificada:

\author{
Rio Vermelho \\ I \\ Tenho um rio que fala em murmúrios. \\ Tenho um rio poluído. \\ Tenho um rio debaixo das janelas \\ da Casa Velha da Ponte. \\ Meu Rio Vermelho. \\ (CORALINA, 2012, p. 29)
}


Até o encontro com o ser feminino confundido com a natureza entre o encontro com o "peixe-homem" que, "todo feito de espinhos e espinhas" desvela a mulher que sempre conviveu com os rios desde o "feto" até os "cabelos brancos":

VII

Rio Vermelho, líquido amniótico

onde cresceu da minha poesia, o feto,

feita de pedras e cascalhos.

Água lustral que batizou de novo meus cabelos brancos.

(CORALINA, 2012, p. 29)

A comparação da mulher à terra é uma imagem recorrente e, conseguintemente, as aproximações entre as memórias e a própria História vão sendo tecidas por meio de tramas narrativas que aludem a um labirinto enigmático da formação do eu lírico em um discurso que reverbera outras vozes anônimas, mas a ela incorporadas, ao mesmo tempo em que mostram suas visões sobre as transformações do país em continuidade com sua própria existência de mulher:

Nossa Senhora das sementes...

Ajudai todas elas - boas e más

a bem cumprir seu destino

de sementes,

lançando do seu pequenino

coração vital

o esporo à raiz fálica

que as confirmarão na terra

e na sequência das gerações

através do tempo.

(CORALINA, 2012, p. 32, grifos meus)

Os corpos violados das mulheres também são temáticas de sua poesia, em personagens que mimetizam a própria luta da mulher entre as cruezas dos fatos anônimos e perfazem a realidade em torno de uma cultura patriarcal a 
naturalizar a apropriação de corpos femininos apenas porque não confinados em espaços ditos reservados às mulheres. A presença da personagem sozinha em um milharal poderia ser a justificativa do destino a ela reservado, já que naturalizado como destino da terra, "genésico" e conceptivo de "tempos" e "idades":

\section{O Cântico de Dorva I \\ Dorva é moça de sítio.}

A mãe de Dorva morreu.

Chovia... chovia...

[...]

Deixa-se cair

sentada, deitada.

Sobre seu ventre liso, redondo

desnudo,

salta o macho.

Um ofego de posse

tácito.

Sexo contra sexo.

Aquele cântico de Dorva,

aquele chamado - piado de fêmea:

obscuro

aflitivo

genésico

instintivo

veio vindo... veio vindo...

Rugindo

chorando

gritando

apelando

do fundo dos tempos

do fundo das idades.

(CORALINA, 2012, p. 35, grifos meus)

Ao demonstrar consciência sobre sua existência, alude aos percalços femininos em uma sociedade de origem patriarcal, em coisas das mais cotidianas, mas não por isso menos violentas como descreve em versos de narrativas simples mas plenos de elaboração social para análise de lacunas históricas que tratam a desigualdade de gênero de maneira sutil e quase imperceptível: "Mas... ai de 
mim!/ Era moça da cidade./ Escrevia versos e era sofisticada./ Você teve medo./ O medo que todo homem sente/ da mulher letrada"(CORALINA, 2012, p. 50). Revelando que é "mais doceira e cozinheira/ do que escritora", defende que a “culinária/ a mais nobre de todas as Artes:/ objetiva, concreta,/ jamais abstrata,/ a que está ligada à vida e/ à saúde humana" (CORALINA, 2012, p. 50). Elabora estranheza metafísica ligada à terra, com uma poesia que desloca sentidos entre o sublime e o mais prosaico, até mesmo na personificação das "Artes" como uma manifestação mais imediata da complexidade existencial.

Dessa forma, a segunda parte, bem mais confessional derrama-se em poesia subjetiva que denota a marcação temporal para um eu lírico que se comunica em primeira pessoa com pronomes possessivos que atestam que o livro de cordel título é de fato composto por narrativas que partem de uma existência muito localizada. Esses encontros sugeridos ao leitor o cerca a ponto de serem resultado da fusão imediata entre poeta e eu lírico que, atados, reivindicam protagonismos imbuídos de outras difusas vozes atreladas ao anonimato do tempo entre as diversas opressões entrelaçadas e justapostas às quais a poeta, nos anos 1970, talvez tenha acompanhado muito mais em seu cotidiano do que por meio do contato com os teóricos do pós-culturalismo dos estudos (multi)culturais, relembra sua ama de leite em passagens que associam as origens escravocratas à formação do país em seus engenhos e fazendas do nordeste que ecoaram em Goiás: "Para você, Mãe Didi, esta página sem brilho/ do Meu Livro de Cordel" (CORALINA, 2012, p. 66).

Dessa forma, posiciona-se diante dos desmandos sociais oriundos das mazelas históricas herdeiras do racismo e das violências ancestrais: "Preconceitos de classe./ Preconceitos de cor e de família./ Preconceitos econômicos./ Férreos preconceitos sociais" (CORALINA, 2012, p. 49). Contudo, já aclamava a arte poética como resistência capaz de ecoar em gerações futuras por meio da "Luta, a palavra vibrante/ que levanta os fracos/ e determina os fortes. Quem sentirá a 
Vida/ destas páginas.../ Gerações que hão de vir/ de gerações que vão nascer". A consciência de que se estava fazendo história e abrindo caminhos revela um trabalho poético engajado em causas emancipatórias da mulher e da poesia, como dupla que provém da terra e a ela resiste continuamente.

Entretanto, a compreensão sobre a criação poética e o pacto da verossimilhança entre o leitor e o escritor transbordam ironicamente em passagens plenas de fingimento poético como "- Perdas e danos, meus acertos./ - Lucros, meus erros./ Daí a falta de sinceridade nos meus versos" (CORALINA, 2012, p. 62) e novamente o enigma da chamada escrita confessional, nos últimos versos dos poemas finais de Meu livro de cordel faz emergir a poeta e questiona a mulher Cora Coralina. Sua elaboração poética erigida em torno do possessivo "Meu" ludibriou a leitura a ponto de ser aceita como testemunhal desde o início de relatos da menina que supostamente havia transformado a vida em cordel, a existência em arte literária. Assim, a própria memória coletiva (HALBSWACHS, 1990) coadunada à História do país é revista. A Literatura se abre interrogativa. Não é relato. É criação afastada alheia ao caráter documental.

Destarte, no poema que encerra o volume, Cora Coralina - a escritora tornada eu lírico de si mesma entre os jogos de autoria e criação -, sem constrangimentos poéticos oferece a fórmula da construção poética ao passo em que, fluida como água corrente e mais do que metalinguagem, exercita um rigor sobre seu ato de escrever como método e testemunho:

\footnotetext{
Também tem o seu direito de figurar no verso.

Tudo isso, mais um conteúdo miúdo que seja e serás Poeta.
}

(CORALINA, 2012, p. 69)

Portanto, ao extrair da escrita a água e a terra, explica os fios da memória que perfazem a própria existência humana transmutada em signos que 
atravessam palavras, imagens e sons para estabelecer dialogismos históricos e discursivos atemporais.

\section{CONSIDERAÇÕES FINAIS}

É possível entrever na obra de Cora Coralina um vigor poético voltado a diversas pautas e discussões teóricas contemporâneas que aludem a interseccionalidades ao tratar da História e suas fissuras de formação (LUGONES, 2008), levantando voz contra opressões que subjugam corpos não considerados em suas complexidades, ou úteis, dóceis e domesticáveis (FOUCAULT, 1997), mesmo em contextos que se revelam surpreendentemente cerceadores das liberdades mínimas individuais, como a vida doméstica. Logo, por mais que não estivesse diretamente filiada a nenhuma reivindicação de questões calcadas na defesa das mulheres ou aos direitos humanos, também se mostrou detentora de uma escrita incansável na sua própria descoberta do que é ser, viver e enfrentar o mundo como uma mulher e, mais, como um corpo subalternizado submetido a disputas de saber e poder.

Apesar de sua idade avançada, escolaridade não acadêmica e trajetória improvável no mundo das Letras, conseguiu comunicar a muitas mulheres suas vivências e seus olhares, de modo prosaico, mas não simplista; e por meio de uma escrita apegada à terra, aos becos, vielas e ao rés do chão. Voltou-se, inclusive, à formação controversa do país e questionou-o por meio de suas riquezas historicamente pautadas por explorações. Sobretudo, como mulher exigiu, telúrica, o direito à terra, ao corpo e à voz, para conseguir fiar, por meio de suas mãos de doceira, narrativas um pouco menos amargas. 


\section{REFERÊNCIAS}

BEAUVOIR, Simone de. A Velhice. Rio de Janeiro: Nova Fronteira, 1990.

BENJAMIN, Walter. "O narrador". In: Magia e Técnica, Arte e Política- ensaios sobre literatura e história da cultura. Obras escolhidas, volume I, 2. ed. São Paulo: Brasiliense, 1994.

BOSI, Alfredo. O ser e o tempo da poesia. São Paulo: Cultrix/Edusp, 1977.

BOSI, Alfredo. História concisa da Literatura. São Paulo: Cultrix, 2015.

CANDAU, Joël. Memória e identidade. São Paulo: Contexto, 2011.

CANDIDO, Antonio. Literatura e Sociedade. 9. ed. Rio de Janeiro: Ouro sobre Azul, 2006.

CANDIDO, Antonio. Na sala de aula. 8. ed. São Paulo: Ática, 2000.

CANDIDO, Antonio. Formação da Literatura Brasileira. 7. ed. Belo Horizonte/Rio de Janeiro: Itatiaia, 1993.

CORAliNA, Cora. Poemas dos becos de Goiás e Estórias mais. São Paulo: Global Editora, 2006.

CORALINA, Cora. Meu Livro de Cordel. 1. ed. digital. São Paulo: Global Editora, 1997

FOUCAULT, Michel. Vigiar e Punir. Petrópolis: Editora Vozes, 1987.

HALBSWACHS, Maurice. Memória coletiva. São Paulo: Vértice, 1990.

LUGONES, María. “Colonialidade e gênero". In: Tabula Rasa. 2008, n. 9, pp. 73-102.

MACHADO, Ana Maria. “O Tao da teia” In: Estudos Avançados, n. 17, vol. 49, São Paulo, 2003.

NORA, Pierre. Entre memória e história: a problemática dos lugares. São Paulo: Projeto História, n. 10, dez. 1993.

PAZ, Octavio. O arco e a lira. Trad. Olga Savary. Rio de Janeiro: Nova Fronteira, 1982.

RICOEUR, Paul. A memória, a história, o esquecimento. Campinas, SP: Editora da UNICAMP, 2007.

Nota do editor:

Artigo submetido para avaliação em: 27 de março de 2021.

Aprovado em sistema duplo cego em: 12 de setembro de 2021. 